\title{
PROBLEMAS INSTITUCIONAIS E PEDAGÓGICOS NA IMPLANTAÇÃO DA REFORMA CURRICULAR DA EDUCAÇÃO PROFISSIONAL TÉCNICA DE NÍVEL MÉDIO NO IFSP*
}

\author{
CELSO JoÃo FERRETTI* ${ }^{* *}$
}

\begin{abstract}
RESUMO: Este texto apresenta e discute a implantação da reforma da educação profissional de nível médio no Instituto Federal de Educação, Ciência e Tecnologia de São Paulo (IFSP), focando as tensões que se produziram em função desse processo. Questiona-se por meio de pesquisa empírica se os Institutos Federais reúnem, na atualidade, as condições necessárias para o desenvolvimento da educação politécnica, na perspectiva marxiana, por intermédio do ensino técnico integrado ao ensino médio.
\end{abstract}

Palavras-chave: Educação profissional e tecnológica. Implantação de reformas educacionais. Ensino técnico integrado ao ensino médio.

\section{INSTITUTIONAL AND PEDAGOGICAL PROBLEMS TO IMPLEMENT THE CURRICULUM REFORM IN THE TECHNICAL-PROFESSIONAL HIGHER EDUCATION AT THE IFSP}

ABSTRACT: This paper presents and discusses the implementation of the reform of higher vocational education at the Federal Institute of Education, Science and Technology of São Paulo (IFSP) focusing on the tensions that arose during the process. Through an empirical research, it questions whether such Federal Institutes are still in a position to provide polytechnic education, such as conceived by Marx, by integrating vocational and academic courses.

Key words: Vocational and technological education. Implementation of educational reforms. Integrated vocational and academic education.

* $\quad$ Este artigo baseia-se em pesquisa realizada entre 2007 e 2009, com financiamento da FAPESP.

** Doutor em Educação e colaborador e pesquisador do Centro de Estudos Educação e Sociedade (CEDES). E-mail: celsojoaoferretti@gmail.com 


\section{Problèmes InSTITUTIONNELS ET PRÉDAgOGIQUES LORS DE LA MISE EN GEUVRE DE LA RÉFORME DES PROGRAMMES D'ÉDUCATION TECHNIQUE ET PROFESSIONNELLE AU F.I.S.P.}

RÉSUMÉ: Cet article présente et discute la mise en œuvre de la réforme de l'éducation professionnelle au lycée à l'Institut fédéral d'éducation, science et technologie de São Paulo (I.F.s.P.), en se centrant sur les tensions ayant surgi au long de ce processus. Une recherche empirique remet en question la capacité de ce type d'Instituts fédéraux, aujourd'hui, à dispenser un enseignement polytechnique dans une perspective marxiste, en intégrant l'enseignement technique et le lycée.

Mots-clés: Formation professionnelle et technologique. Mise en œuvre des réformes éducatives. Enseignement technique intégré au lycée.

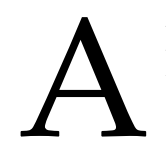

pós tecer elogios à administração Lula pela expansão da rede de instituições profissionais, o ministro da Educação exaltou as contribuições dos Institutos Federais (IF) como modelos institucionais em condições de promover "uma atuação integrada e referenciada regionalmente", de acordo com alguns dos pilares do Plano de Desenvolvimento da Educação. No tocante à oferta de cursos, ressaltou a observância da "sintonia com a consolidação e o fortalecimento dos arranjos produtivos locais", o estímulo "[à] pesquisa aplicada, [à] produção cultural, [ao] empreendedorismo e [ao] cooperativismo" e o apoio aos "processos educativos que levem à geração de trabalho e renda, especialmente a partir de processos de autogestão" (Haddad, 2008, p. 18-19), reiterando, no nosso entender, pelo menos alguns dos propósitos que se fizeram presentes nos discursos dos documentos de reforma do ensino médio e do ensino técnico, produzidos na gestão FHC.

Ao tratar do ensino médio, o ministro foi especialmente otimista ao conferirlhe destaque no que tange à missão dos If de "ofertar educação profissional e tecnológica, como processo educativo e investigativo". Na sua visão, tais instituições promoveriam

(...) a combinação virtuosa do ensino de ciências naturais, humanidades (inclusive filosofia e sociologia) e educação profissional e tecnológica - o que deve contemplar as formas de organização da produção - [repondo, com isso], em novas bases, o debate sobre a politecnia, no horizonte da superação da oposição entre o propedêutico e o profissionalizante. (Idem, ibid., p. 19)

Todavia, tal separação não se deve apenas às disposições legais, mas, principalmente, ao caráter econômico-social da dualidade estrutural "socialmente determinada pela contradição entre capital e trabalho" (Kuenzer, 2010, p. 862). Por isso, não pode ser superada no plano educacional e, especificamente, no pedagógico. 
Além disso, segundo a autora, ocorre uma "mudança na forma de objetivação desta [dualidade] em face das mudanças ocorridas no mundo do trabalho a partir do novo regime de produção flexível" (p. 863), que implica a sua inversão.

Em decorrência, não há mais como afirmar que a educação profissional se destinaria prioritariamente, como antes, ao preparo da classe trabalhadora para a ocupação de postos de trabalho que demandariam, no máximo, a formação técnica de nível médio. Na perspectiva hoje concretizada, a educação profissional e tecnológica constitui-se no itinerário formativo verticalizado que tem seu horizonte ampliado para o pós-doutorado. Um itinerário que já era possível, mas que, hoje, torna-se sistêmico, podendo ser trilhado a partir de uma única instituição pública. A inversão anteriormente referida apoia-se na hipótese, aventada por Kuenzer (op. cit., p. 863), de que "a educação geral, antes reservada à elite, quando disponibilizada aos trabalhadores, banalizou-se e desqualificou-se", ao passo que a formação de melhor qualidade ofertada pelos IF, altamente seletivos, passou a ser disputada pela classe média.

Não se trata de negar a importância do domínio do conhecimento técnico e tecnológico ou de suas bases científicas ou de criticar a criação de facilidade de acesso da população a tais conhecimentos, mas, sim, de criticar a valorização desse domínio a partir de um olhar que nos parece restritivo, por três razões: a) pela ênfase da formação no domínio da técnica e a tecnologia, em detrimento de outras esferas; b) pela pouca ênfase conferida ao exame dos contextos políticos, econômicos, sociais e culturais na produção do conhecimento científico e tecnológico; c) por tomar como referência o mercado e a visão economicista de mundo. Tal visão transparece em expressões e termos tais como formação por competência, empreendedorismo, autogestão, abundantemente empregados nos discursos reformistas do governo FHC e retomados de forma amenizada no governo Lula.

A investigação em pauta, realizada entre 2007 e 2009, teve por objetivo principal analisar os desdobramentos da implementação do Decreto n. 2.208/97 na organização, na dinâmica, no ethos institucional e nas práticas dos professores do ensino técnico do IFSP, bem como as implicações resultantes das possibilidades de reversão da referida legislação a partir do Decreto n. 5.154/04.

Seu desenvolvimento pautou-se no pressuposto de que, apesar das expectativas dos reformadores, a escola não é mera executora do que dela pretendem os formuladores de política. Entende-se que, como coletivo, ou pela ação de professores ou grupos de professores, podem ser realizadas escolhas, mesmo limitadas, entre alternativas de formação. Tais escolhas, no nosso entender, dependem das apropriações que a escola realiza das políticas propostas e das objetivações ${ }^{1}$ delas resultantes, as quais tomam a forma de práticas gestionárias e pedagógicas. 
Cabe esperar, segundo Ball (1989), em seu exame da micropolítica institucional, que a implantação de reformas nas escolas produzam movimentos convergentes e antagônicos em relação a tais propostas, a partir de valores divergentes, concepções político-ideológicas distintas e grupos de interesses díspares, o que acaba por gerar enfrentamentos menos ou mais abertos e, portanto, conflitos. Referindo-se aos docentes, Ball chama de interesses criados "as preocupações materiais dos professores relacionados às condições de trabalho: as remunerações, a carreira, as promoções, [que se tornam] fonte de disputa entre pessoas e grupos" (1989, p. 33), de interesses pessoais aqueles que se referem à identidade declarada ou aspirada pelo professor e de interesses ideológicos os que concernem a questões valorativas e de adesão filosófica.

Segundo o autor, nem tudo na dinâmica escolar diz respeito a conflitos, havendo espaço para negociações e consensos. O consenso e a diversidade se explicam, em parte, pelo fato de que, como instituição social, cada escola se constitui historicamente, dando margem a uma forma própria de ser, que não é alheia ao contexto político, econômico, social e cultural em que está inserida e que, por isso mesmo, não é estática, mas muda, lentamente ou com alguma rapidez, pela incorporação, ora passiva, ora crítica, das proposições políticas que lhe são feitas. A escola apresenta-se, assim, mais do que espaço de conflitos, como palco de contradições, revelando-se, simultaneamente, favorável à mudança e defensora de práticas que privilegiam as tradições.

Os procedimentos de pesquisa consistiram no levantamento e análise de vários documentos institucionais e de dissertações e teses produzidas por professores da própria instituição até 2007 , que tivessem por objeto a implementação, nela, da reforma do ensino técnico e do ensino médio, ${ }^{2}$ bem como na realização de 22 entrevistas envolvendo professores de dois campi da instituição: o campus-sede, localizado em São Paulo, e o campus de Sertãozinho, no interior do estado. ${ }^{3}$

A análise dos documentos permitiu compreender o processo histórico da constituição da Escola Técnica Federal de São Paulo (ETFSP) no que se refere à sua transformação no Centro Federal de Educação Tecnológica de São Paulo (CEFET-SP). De acordo com nossa hipótese inicial, apesar de compartilhar com as instituições congêneres vários procedimentos em relação à implementação das reformas da década de 1990, o CEFET-SP trilhou alguns caminhos próprios.

No que diz respeito aos aspectos comuns aos diferentes CEFET, verificou-se a vinculação de tal implementação ao acesso a recursos financeiros oriundos de agências multilaterais, a tendência a adotar as recomendações do MEC relativamente à estruturação dos cursos médio e técnico, à oferta de cursos em diferentes níveis (formação profissional básica, técnica e tecnológica), à implementação de 
cursos superiores de tecnologia e de formação de professores para o ensino técnico, à sinalização do interesse em investir na pesquisa aplicada no campo da tecnologia e, de forma cabal, à busca da estreita relação entre a formação oferecida e as demandas empresariais, na linha do que Lima Filho (2002) denominou de desescolarização. ${ }^{4}$ Razões da mesma natureza estiveram presentes na implementação da reforma do ensino técnico encetada no Rio Grande do Norte pelo CEFET-RN, no final da década de 1990 e início da seguinte (cf. Pereira, 2010, p. 261). ${ }^{5}$

Quanto aos caminhos próprios percorridos pelo CEFET-SP, verificou-se que o processo de "cefetização"/implementação das reformas gerou a produção de um Projeto Pedagógico em 1997/1998 que, ao mesmo tempo, buscou contemplar as recomendações do MEC e, de outro, introduzir uma leitura institucional própria que resultou em encaminhamento marcado pela ambiguidade. Os elementos coletados a partir da análise das dissertações e teses selecionadas e das entrevistas permitiram verificar que vários aspectos caracterizam o processo de implantação tanto do proposto pelos decretos n. 2.208/97 e 5.154/04, quanto da verticalização experimentada pela instituição.

O primeiro aspecto que ressalta diz respeito ao processo de transformação da ETFSP em CEFET-SP. A direção da época desenvolveu, desde 1996, ações no sentido de produzir tal transformação, no que era acompanhada, em termos gerais, pelos professores. Havia, portanto, sob esse aspecto, convergência de interesses entre essas duas instâncias. Todavia, como apontado por Mergulhão (2003), o processo tornou-se traumático e marcado por tensões e conflitos entre a direção e professores e também entre estes, na medida em que foi interpretado por muitos docentes como açodamento da direção, resultando em algo não desejado: a implantação apressada da reforma, que colocava por terra o modelo de ensino técnico resultante da Lei n. 5.692/71, denominado doravante ET/71, muito prezado por eles, porque conferia prestígio à escola e, por isso, a eles próprios. Ao mesmo tempo, o referido processo implicou disputas internas quanto à aceitação ou não da estrutura curricular de formação por competência, amplamente criticada por educadores afinados com os interesses dos trabalhadores desde a proposição do Projeto de Lei n. 1.603/96 e sua transformação no Decreto n. 2.208/97, complementado pelas Diretrizes Curriculares Nacionais tanto do ensino médio quanto da educação profissional de nível técnico. Pereira (2010) refere-se à ocorrência de processo análogo ocorrido no CEFET-RN.

Estiveram em jogo, sob esse aspecto, os interesses ideológicos dos professores, expressos na sua concepção do que seria uma boa educação técnica, seus interesses pessoais, na medida em que a educação então oferecida era consistente com sua identidade profissional, assim como seus interesses criados, dado que a transformação da ETFSP em CEFET-SP lhes possibilitaria, em tese, construir uma carreira que não se encerraria no âmbito de um curso técnico de nível médio. Da mesma 
forma, estiveram em jogo os interesses ideológicos da direção e dos que com ela se afinavam, expressos na aceitação político-administrativo da reforma, amarrada pelo governo federal à transformação institucional antes referida e, certamente, no exercício do controle administrativo sobre tais modificações. Essa diversidade de interesses resultou, de um lado, na meta comum de promover a transformação da ETFSP em CEFET-SP, mas, também, em diversidade de metas em relação ao destino do ensino técnico então ministrado pela instituição.

Estreitamente associado a este aspecto avulta outro, relativo à aceitação, ou não, dos argumentos governamentais para promover, por meio da reforma, a separação entre o ensino médio e o ensino técnico. Tais argumentos giraram em torno da elitização da escola e do "desvio" representado pela opção dos egressos de dirigirse à universidade e não ao trabalho fabril. Tanto os estudos resenhados quanto as entrevistas mostraram haver divergências entre os professores, alguns deles concordando com a possível democratização do acesso e outros se manifestando contrários a ela ou, pelo menos, contrários aos efeitos que tal processo teria sobre a qualidade dos cursos técnicos até então oferecidos.

Neste caso, avultaram os interesses ideológicos dos professores: de um lado, a defesa da permanência de um processo seletivo rigoroso, que permitiria, a par da manutenção do antigo ensino técnico (AET), a excelência de qualidade até então desfrutada pela escola; de outro, a defesa da democratização do acesso, mas correndo-se o risco de admissão de alunos com menor capital cultural e social que, a par da pretendida separação entre o ensino médio e o ensino técnico, poderia promover, como ocorreu, conforme o testemunho de vários dos entrevistados nesta pesquisa e nas produzidas por docentes da instituição, a perda da qualidade até então presente. Não por acaso, esse foi um tema continuamente reiterado nas entrevistas.

Em vários momentos, os comentários críticos sobre o precário cabedal escolar demonstrado por alunos matriculados nos cursos sequenciais/concomitantes originados pela reforma dirigiram-se, adequadamente, à precária qualidade do ensino oferecido pelas redes municipais e estaduais de São Paulo, mas, em outros, ainda que poucos, resvalaram para o preconceito em relação a tais candidatos. Impressões semelhantes foram registradas por Oliveira (2002) no âmbito de um CEFET.

É interessante recuperar, neste caso, a identificação feita pelos professores entrevistados por Fernandes (2007) entre os cursos sequenciais/concomitantes montados em decorrência da reforma e os antigos cursos complementares oferecidos pela escola na década de 1970 e desativados em 1980, dirigidos a uma população semelhante à que acorreu à instituição em decorrência da democratização do acesso. Segundo tais professores, os cursos complementares eram "cursos menores", com os quais a escola "não tinha grande preocupação". O destaque se justifica na medida 
em que revela a hierarquização discriminatória, já existente, que aflora novamente com os cursos sequenciais/concomitantes.

As críticas dos professores ao modelo são, por outras razões, procedentes. A separação entre ensino médio e ensino técnico, a modularização, a obrigatoriedade dos alunos, na modalidade concomitante, de frequentarem dois cursos simultaneamente, a diminuição da duração dos cursos técnicos, obrigando a restrição dos conteúdos tratados nos AET, ou sua compactação, aliados à precária escolarização da população atendida constituíram-se, em seu conjunto, em forte limitação ao desenvolvimento de cursos de qualidade.

Apesar de Mergulhão (2003) reportar que os debates internos explicitaram posições ideológicas, políticas e corporativas, as críticas dos docentes se dirigiram mais às decorrências de caráter funcional relativas à implantação da reforma e menos a seus aspectos teórico-filosóficos. A julgar pelo conteúdo das entrevistas, pouca discussão foi travada em torno do espírito da reforma, isto é, das suas dimensões sociais, políticas, econômicas e culturais e, por estranho que pareça, também das educacionais, a não ser por parte dos docentes da área técnica que, articulados com os das áreas de formação propedêutica, estiveram à frente da discussão do Projeto Pedagógico (PP) de 1998. A participação dos demais se restringiu às discussões referentes à construção das grades curriculares dos cursos técnicos. Esse aspecto chama a atenção, uma vez que, no período em que ocorreram as discussões sobre o PP (1997/1998), já havia alguma literatura a respeito da reforma e das propostas curriculares que produzia críticas contundentes à formação por competência (por exemplo, entre outros, Hirata, 1994; Ferretti, 1997; Kuenzer, 1997, Ropé \& Tanguy, 1997; Dugué, 1998; Machado, 1998).

O desinteresse no debate de caráter político-pedagógico, especialmente se apresentados em longos textos, como no caso do pp de 1998, foi exemplarmente explicitado na manifestação do professor Amauri, referindo-se não apenas à visão "tecnicista" prevalecente entre os professores da área técnica, mas também à postura pouco crítica e política da(s) direção(ões) da instituição frente às determinações do governo federal. Tal ausência de disposição pode ter determinado que a discussão propriamente educacional e pedagógica das proposições curriculares da reforma fosse relegada a um segundo plano, contribuindo tanto para que a formação por competência não ocorresse na escola, apesar do discurso institucional do qual consta formalmente, quanto para sua negação com base em argumentos de caráter político e ideológico.

Todavia, é preciso levar em conta que há uma aparente aproximação, tanto neste estudo quanto nos que foram resenhados, entre as críticas de boa parte dos professores entrevistados e aquelas assumidas por vários educadores progressistas, 
no que tange a um aspecto da reforma: a separação, promovida por esta, entre formação geral e formação específica, ou, como disseram tais professores, entre teoria e prática. $\mathrm{O}$ caráter aparente dessa aproximação será objeto de consideração mais detida quando da discussão das disputas de interesses em torno do Ensino Técnico Integrado (ETI).

Os posicionamentos trazidos à baila nos parágrafos anteriores representam uma das manifestações do conflito mais profundo e permanente que atravessa as instituições de formação profissional - o existente entre as áreas e disciplinas de formação geral e as de formação específica -, o qual, por sua vez, parece ser também manifestação de embates mais amplos referentes às relações entre o campo das ciências humanas e das ciências exatas e naturais. No nosso entender, as reformas do ensino técnico e do ensino médio promovidas pelo governo de Fernando Henrique Cardoso, às quais o governo Lula deu continuidade, na sua essência, reafirmaram tal dicotomia.

No caso específico da instituição pesquisada, esse conflito - latente desde o período em que vigorava o Eт/71, mas, de alguma forma, negociado, naquela época, por meio de um arranjo em que as disciplinas de formação geral serviam de suporte ao desenvolvimento das de formação específica - veio à tona de forma explicita nas manifestações recolhidas entre os professores, com fundamento nos interesses criados. Estes, relativos às condições de trabalho e, mais especificamente, à preservação da situação funcional, manifestaram-se, nos primórdios da implantação da reforma na instituição, tanto por parte dos professores das disciplinas de formação geral, quanto dos vinculados ao ensino técnico, por meio da busca de alternativas à possível diminuição do número de aulas pelas quais eram responsáveis. No caso dos primeiros, essa alternativa se materializou por meio da oferta de ensino médio pela instituição, como um curso separado e, também, por meio da criação dos cursos superiores de licenciatura para a educação básica. No caso dos segundos, a materialização se deu por meio da oferta do ensino técnico separado do ensino médio e, também, por intermédio da sua participação nos cursos superiores de educação tecnológica. Tais alternativas, legalmente permitidas pela legislação reformista e por aquela referente aos antigos CEFET, reproduziram a dicotomia anteriormente citada e, por essa forma, o conflito latente.

No final de 2008, o IFsP decidiu, com base no Decreto n. 5.154/04, manter o modelo sequencial/concomitante e oferecer simultaneamente o ETI, o que teoricamente facilitaria, neste último caso, a integração entre formação geral e específica. A medida gerou posturas contraditórias. De um lado, houve reações negativas, pois vários professores entenderam que o decreto representava mais uma imposição governamental além da que tinham sofrido com o Decreto n. 2.208/97. De outro, perceberam o ETI como possibilidade de retorno ao ETI/71 e, por isso, avaliaram positivamente sua implantação. Rodrigues (2010), em seu estudo sobre a implantação do ETI no 
Instituto Federal do Mato Grosso (IFMT), tece considerações muito próximas às dos professores do IFSP no que respeita às "imposições" de política por parte do MEC.

A medida também acirrou o conflito em função da necessidade de revisão das grades curriculares. Novamente os interesses criados, inclusive os ideológicos, se tornaram orientadores das discussões. Segundo os professores entrevistados, a distribuição da carga horária entre as disciplinas de formação geral e as disciplinas específicas favoreceu as primeiras em detrimento das segundas. Além disso, avaliaram negativamente que tal distribuição promoveria uma inversão em relação ао Ет/71: nо Еті as disciplinas de formação geral deixariam de "servir" ao ensino técnico, como naquele e, nesse sentido, "desvirtuariam", de certa forma, a missão histórica da escola, que seria a de formar técnicos. A produção de D’Angelo (2007) reitera essa avaliação. Por essa razão, deu-se, após a decisão interna de implantação do ETI, um processo de negociação no sentido não de diminuir a carga horária das disciplinas de formação geral, pois isso contrariaria a legislação, mas de aumentar a carga horária das disciplinas técnicas, ampliando a carga total do curso, posto que a estipulada legalmente é a mínima a ser observada para fins de titulação dos alunos. Além disso, segundo alguns depoimentos, o fato do ensino médio oferecido pelo antigo CEFETSP ter se salientado nas avaliações nacionais fez com que os professores a ele vinculados passassem a recusar, no ETI, o papel que anteriormente lhes era conferido, enquanto os professores do ensino técnico aparentemente esperavam que fosse reiterado, o que aumentou o potencial do conflito.

Cabe produzir um questionamento ao discurso dos docentes que atribui a um movimento interno seu o processo de implantação do ETı na instituição. Deve-se reconhecer que a insatisfação interna com relação à separação entre ensino médio e ensino técnico, à modularização e mesmo à formação por competência contribuiu para a implantação do ETI na instituição, mas é necessário considerar que, desde 1998, quando se deu a implantação do Decreto n. 2.208/97, decorreram quase dez anos até que o ETI passasse a fazer parte da vida institucional. Tal possibilidade existia, do ponto de vista da legislação, desde a Lei n. 9.394/96 e, mais tarde, desde o Decreto n. 5.154/04. Todavia, há que fazer justiça ao IFSP, nesse particular, pois, como nas demais instituições educacionais do país, a implantação do ETI, quando ocorreu, só se deu após a promulgação do referido decreto.

Por outro lado, a leitura que os professores realizaram do ETı não faz justiça nem a seus propositores (Frigotto, Ciavatta \& Ramos, 2005), nem ao espírito que animou o Decreto n. 5.154/04. Além de representar a negação da formação por competência, a proposição nuclear do Decreto apoiou-se na concepção de uma educação de caráter integrado, politécnico, omnilateral, no sentido que lhe emprestam tanto Marx quanto Gramsci, enquanto os professores o entenderam simplesmente como a possibilidade de retomada do ET/71. 
Embora deva se reconhecer a qualidade do ensino oferecido pela instituição naqueles moldes, ela dista muito das proposições de Frigotto, Ciavatta e Ramos (2005, p. 15), quando se referem ao "ensino médio de quatro anos que, de forma articulada e integrada a uma formação científico-tecnológica e ao conhecimento histórico social, permitam ao jovem a compreensão dos fundamentos técnicos, sociais, culturais e políticos do atual sistema produtivo". Quando Marx e Gramsci se reportam à escola, pretendem que ela contemple a formação técnica, mas não se encerre nela, nem na mera aquisição de informações. Gramsci, em particular, estabelece estreita associação entre a ação cultural como estratégia da luta política e a educação escolar, pois percebe a escola como elemento central, embora insuficiente, no processo de desenvolvimento intelectual-moral do homem-massa, tendo em vista a constituição da sociedade socialista. O que se propõe não é a adaptação dos sujeitos sociais a novas configurações de um mesmo modo de produção (no caso, o capitalista), mas sua superação.

A postura observada no IFSP em relação ao ETI é aparentemente diversa da que foi encontrada por Nessralla (2010) no curso de Química do Campus I do CEFET-MG. Diversa porque, segundo a autora, não só "o ensino médio integrado foi retomado na instituição em 2005” (p. 165; grifo meu), como também o Projeto Pedagógico Institucional pautou-se pela perspectiva da educação politécnica e tecnológica fundada no trabalho, na ciência, na tecnologia e na cultura, tal como defendido por Frigotto, Ciavatta e Ramos (2005). No entanto, quando a autora se reporta aos professores que entrevistou, fica claro que há diferenças entre eles quanto à concepção do que seja o ensino médio integrado. Alguns o entenderam na sua correta acepção. Outros, entretanto, como no IFSP, atribuíram ao ensino médio tão somente o papel de subsidiar o ensino técnico, tendo em vista a perspectiva de formação para o mercado de trabalho, evidenciando-se, dessa forma, o distanciamento entre o proposto no projeto pedagógico e a prática pedagógica efetiva de pelo menos parte dos docentes. Situação semelhante é reportada por Virote (2009), em sua pesquisa sobre as políticas institucionais do Instituto Federal de Educação, Ciência e Cultura de Goiás (IFG), relativamente à implementação do ETı, em particular no Curso Técnico de Edificações, objeto de seu estudo. A mesma situação é mencionada também por Rodrigues (2010), em seu estudo relativo ao IFMT, e por Pereira (2010), quando se reporta à tentativa de implementação do ETI no atual IFRN.

Por outro lado, Nessralla evidencia em sua pesquisa uma forma de organização do trabalho nos Institutos Federais que tende a isolar os professores em seus cursos, de modo que a interlocução, mesmo entre professores da área técnica, é pouco comum e menos comum ainda destes com os professores de formação geral. Situação semelhante foi encontrada por mim no IFSP (era comum entre professores que entrevistei a utilização do termo "feudo" para reportarem-se aos diferentes cursos técnicos), por Virote, no IFG, e por Grishke e Hypólito (2009, p. 111), no Instituto 
Federal de Pelotas (IFPEL), para quem os "subgrupos têm baixa permeabilidade, permanência elevada, identidade pessoal [com o grupo] e forte organização política, [sendo] também repertório de interesses próprios". Tende, por isso, a ser baixa a disposição para trabalhos que impliquem articulação, reduzindo a integração, portanto, àquela que se desenvolve intragrupo, em função das angústias vividas pelos professores que visam promover alguma integração, apesar da estrutura escolar existente, como deixa entrever o trabalho de Nessralla (2010).

Nessas circunstâncias, obviamente torna-se muito difícil, como foi verificado no IFSP, a perspectiva do pleno desenvolvimento do ETI. A superação desses obstáculos implica não apenas "a geração de tempos e espaços docentes e discentes para a realização de atividades coletivas" (Virote, 2009; resumo), como também o incentivo e a criação de condições para o debate teórico-político sobre a proposta do ETı e seus desdobramentos pedagógicos. No entender de Pereira (2010), a efetivação do ETI em instituições como o IFRN implica uma série de medidas, dentre as quais cabe destacar o aprofundamento teórico-prático da concepção de integração curricular, disposição coletiva (gestores, professores e demais profissionais da educação e alunos) para promover a implementação da proposta, financiamento adequado e permanente, condições objetivas para a oferta consequente do ETI, formação, não apenas dos professores, mas também de gestores e demais profissionais da educação, bem como do pessoal técnico-administrativo da instituição, no que se refere aos fundamentos da proposta de integração entre o ensino médio e a educação profissional técnica, tal como avançada pela perspectiva da formação politécnica e omnilateral.

Aos conflitos históricos existentes na instituição adicionaram-se recentemente outros, motivados pelo intenso processo de verticalização que dela tomou conta no curto espaço de dez anos. Como relatado, as direções entusiasmaram-se, desde cedo, com a perspectiva da verticalização e trabalharam para que esta acontecesse. Os professores, no entanto, dividiram-se a respeito. Entre as críticas, avultam as que, apesar de poucas, apontam para a "perda de identidade" da escola (voltada tradicionalmente para o ensino técnico de nível médio), pois elas se relacionam, de certa forma, com aquilo que Ball denominou de "interesses pessoais" dos professores, no caso, sua identidade como professores dessa modalidade de ensino.

Outras dessas críticas apoiam-se nos "interesses criados", conforme Ball (1989). Elas se reportam, de um lado, à multiplicação apressada dos campi que se espraiaram pelo interior do estado de São Paulo sem que estivessem, no entender de alguns entrevistados, criadas as estruturas e as condições de trabalho necessárias para a oferta de ensino de boa qualidade e, de outro, aos efeitos negativos da verticalização para o ensino técnico, que acabaria por perder espaço para os cursos de nível superior e, mais que isso, tenderia a ser desvalorizado, isto implicando a desvalorização profissional dos docentes vinculados ao primeiro. 
Todavia, os interesses pessoais e criados por professores afetados por esse processo podem ser, de alguma forma, compensados, seja pela atuação do governo federal, obrigando a destinação de $50 \%$ das vagas oferecidas pela instituição ao ensino técnico, seja pela possibilidade, garantida pelo regime de contratação, de que os professores possam dividir sua jornada entre os cursos superiores, o curso técnico e o PROEjA, o que, obviamente, acarreta sobrecarga de trabalho, implicando, como assevera Hypólito (2010, p. 1346), "mais tarefas e responsabilidades extras, mais relatórios e registros escolares, maior intensificação do trabalho, menor tempo para preparação e estudo".

O aspecto mais polêmico da verticalização relaciona-se com o novo plano de carreira profissional estabelecido pelo governo federal, dado que ele desencadeou o processo de valorização da titulação acadêmica em detrimento do tempo de trabalho. Tal procedimento implica a remuneração muito diferenciada para a realização de trabalho da mesma natureza. Evidentemente, a hierarquização dos docentes segundo sua titulação afetou os interesses criados de professores que, por vários anos, vêm trabalhando na escola. $\mathrm{O}$ mal estar produzido só não foi maior porque a carreira trouxe benefícios mesmo para esses professores. Todavia, também abriu a possibilidade de surgimento de novos conflitos, dada a existência de posicionamentos valorativos favoráveis e desfavoráveis que produziram avaliações concernentes, por exemplo, à capacidade dos doutores de desenvolverem ensino técnico de qualidade sem terem passado pela experiência da prática que muitos dos antigos professores, ex-alunos da escola, viveram. Ou concernentes à pressão sentida por esses mesmos professores para realizarem cursos de mestrado e doutorado, determinada, seja por razões de remuneração, seja por razões de ordem acadêmica. Nesse sentido, a contingência, criada pela transformação da antiga ETFSP em IFSP, faz com que passem a ser valorizadas de forma ambígua as relações entre pesquisa e ensino, teoria e prática, experiência profissional prática e titulação acadêmica.

Deve-se considerar que o conjunto de relações e conflitos analisados ocorre no contexto de uma instituição cuja organização é muito centralizada e burocratizada, estruturada mais nos moldes da administração sistêmica do que no enfoque da micropolítica da escola, tal como proposto por Ball (1989). Nesse sentido, os conflitos, ao invés de serem entendidos como parte integrante da vida institucional, tendem a ser percebidos como disfunções a serem corrigidas. Esta característica, aliada à forma pela qual a reforma chegou à escola, marcou muitos dos desenvolvimentos posteriores aí verificados.

A proposta reformista pautada pelo cerceamento das possibilidades de participação, pela ausência de debates, críticas e propostas do corpo docente e de setores técnico-administrativos reflete uma dinâmica impositiva e/ou arbitrária de implantação da reforma no espaço escolar, aliada a estratégias dentre as quais se destaca a 
democratização (Fernandes, 2007), como meio de diluir e esvaziar possíveis resistências à materialização da agenda reformista.

Nessa perspectiva, a implementação, tanto do disposto no Decreto n. 2.208/97, quanto no Decreto n. 5.154/04, tende a ser considerada, no plano interno, predominantemente em sua dimensão funcional, isto é, voltada à consideração das razões que impediram ou dificultaram sua melhor adequação e /ou adaptação ao perfil da escola. Nesse sentido, são criticadas a insuficiência de recursos, as condições contratuais dos docentes, a ausência de laboratórios, as carências na capacitação do corpo docente como entraves para o melhor funcionamento ou a melhor adequação das diretrizes postas pela Reforma da Educação Profissional. Tal dimensão não é destituída de sentido. Afinal, as condições de trabalho adequadas, a existência de infraestrutura e de recursos financeiros para a realização das atividades, bem como o preparo profissional dos professores para realizá-las constituem elementos da realidade necessários para viabilizar o pretendido pela instituição.

No entanto, sua mera existência não resulta em garantia de que uma determinada proposta educativa seja colocada em prática. O IFSP e as escolas estudadas por outros pesquisadores e referidas neste trabalho são integrantes de uma rede federal de educação profissional, cuja finalidade principal, apregoada na legislação correspondente e reproduzida em seus regimentos, é a de formar pessoas que bem desempenhem suas atividades profissionais específicas, finalidade esta que, perseguida por décadas, no caso brasileiro, define a cultura educacional e ideológica própria dessa rede que se manifesta nas escolas pertencentes a ela, matizadas por suas particularidades, tornando-as, de um lado, semelhantes entre si e, de outro, diversas, como deixaram entrever os relatos apresentados. Tal cultura é, em certa medida, fruto das experiências vividas pelos que atuam nessas escolas. No plano mais geral, decorre das demandas dos setores produtivos e de serviços que constituem a forma de produção capitalista, a qual determina não apenas o desenvolvimento de inovações tecnológicas, como também uma particular sociabilidade e, nesse sentido, expectativas sociais, culturais e econômicas em relação à educação. Pode-se dizer que, de certa maneira, ela conforma, no sentido lukacsiano anteriormente referido, o caráter das apropriações que os professores realizam do que lhes é proposto, as quais, por seu turno, orientam, por meio de várias mediações, as objetivações que produzem na sua prática (as aulas, os materiais didáticos, entre outros).

Afinados com tal cultura, os professores do IFSP, contrariamente ao que deles se esperava em relação à separação entre o ensino médio e o ensino técnico e em relação à formação por competência, acabaram, passados os anos iniciais de disputa, por manifestarem-se enfaticamente contrários à primeira dessas medidas, por considerarem que ela conduzia ao rebaixamento da qualidade do ensino técnico 
oferecido pela escola. Quanto ao modelo de formação por competência, vários deles afirmaram, sem pesar, que ela simplesmente não havia ocorrido no interior da escola. Embora isso possa soar estranho, uma vez que a proposta da reforma pretendeu fortalecer a cultura acima referida, cabe hipotetizar, de um lado, que a experiência exitosa anterior das escolas técnicas, desenvolvidas em um período de escolaridade de longa duração (quatro anos) e, de outro, que a pouca familiaridade dos professores com a proposta de formação por competência parece tê-los conduzido à reafirmação de suas práticas pedagógicas anteriores, adaptadas ao tempo mais curto de duração dos cursos. Assim, o modelo acabou por não ser posto em prática menos por opção teórica ou ideológica e mais pela limitação ora referida, sem ferir, no entanto, a cultura e a ideologia vigentes na rede.

No que tange à implantação do ETI, com base no Decreto n. 5.154/04, as discussões anteriores evidenciaram, no IFSP, a existência de vacilações e procrastinações a respeito. Por outro lado, nos outros Institutos Federais referidos no decorrer do texto, parece clara a existência de distância entre a disposição de desenvolver o ETI, manifesta nos Projetos Pedagógicos, e as práticas pedagógicas efetivas que vêm ocorrendo no interior das instituições. Embora não tenha consultado o PDI do IFSP, pelo fato de que sua redação estava ainda em processo quando a pesquisa foi concluída, levanto a hipótese de que a mesma situação deve estar ocorrendo também nessa instituição. Cabe indagar as razões para isso. A mesma matriz cultural e ideológica anteriormente referida, ao lado da "feudalização" dos cursos, parece ter orientado o processo tanto no IFSP, quanto nos demais institutos abordados. A "feudalização", pelas razões já referidas; a matriz, porque tendeu a estimular uma espécie de retorno ao AET que havia produzido bons resultados anteriormente.

No entanto, um terceiro aspecto deve ser considerado. Trata-se, no caso da implantação do ETI, de algo semelhante ao que ocorreu com o modelo de competência, ou seja, a pouca familiaridade dos professores com os fundamentos políticoideológicos da proposta de integração entre formação geral e específica na linha da formação politécnica e omnilateral, tal como pensada a partir de Marx e Gramsci e, por extensão, com as possibilidades de sua operacionalização em termos pedagógicos. Não por acaso, mais de um dos estudos de caso relatados no decorrer do artigo alude à necessidade de que os profissionais que atuam nos Institutos Federais entrem em contato com a literatura e respeito e recebam formação que os habilite a desenvolver a proposta.

Apesar do ETI não desvalorizar o desenvolvimento de conhecimentos e destrezas técnicas, propõe a formação mais ampla e complexa que permita, para além do bom desempenho profissional, a apreensão crítica da forma de ser e produzir sob o capitalismo. Isso implica, entre outras aquisições, o acesso qualificado e reflexivo ao acervo das objetivações humanas que se manifestam nos conhecimentos 
historicamente acumulados. Tal processo exige, em benefício da apropriação mais profunda do conhecimento, o estabelecimento de interrelações entre saberes de diferentes áreas e sua contextualização social, cultural e política, captando suas determinações históricas, tanto quanto o domínio de capacidades como as de analisar, questionar, problematizar, interpretar, entre outras, de modo a contribuir para a reforma intelectual-moral do trabalhador a que alude Gramsci.

Os elementos dispostos alertam para a necessidade de desenhar com maior cautela as expectativas oficiais em torno das contribuições que os Institutos Federais possam oferecer no sentido de "repor, em novas bases, o debate sobre a politecnia, no horizonte de superação da oposição entre o propedêutico e o profissionalizante" (Haddad, 2008, p. 19). Há, evidentemente, um longo caminho a percorrer, especialmente se a educação politécnica for entendida na perspectiva marxiana, ou seja, como ação política e não apenas como estratégia pedagógica.

\section{Notas}

1. Os termos destacados têm como referência as formulações de Lukács (1981) a respeito do caráter ontológico do trabalho como protoforma da constituição do ser social. De acordo com o autor, no processo histórico de sua constituição como humanos, os homens desenvolveram, no convívio com a natureza e nas relações sociais, a capacidade de pré-ideação, ou seja, de antecipar na mente os fins a atingir. A realização destes, ou seja, a objetivação de sua subjetividade, implicaria a apropriação de elementos da realidade natural e social de modo a constituir alternativas de ação.

2. Foram localizados cinco trabalhos (Mergulhão, 2003; Matias, 2004; Villela, 2007; D'Angelo, 2007; Fernandes, 2007).

3. O campus de Sertãozinho foi selecionado em função da informação institucional, disponibilizada no início da pesquisa em 2007, de que ali ocorria a implementação do Ensino Técnico Integrado (ЕTI), o que não se confirmou.

4. A "desescolarização" refere-se às concepções desenvolvidas na década de 1980 pelo cinTERFOR a respeito das perspectivas para o ensino técnico, tendo em vista as transformações no âmbito do trabalho que estavam em processo desde a década de 1970. Sinteticamente, tais concepções afirmavam que essa modalidade de ensino guiava-se, na América Latina, mais pela visão escolar do currículo do que pela relação com as empresas, resultando tal postura no relativo distanciamento entre o que o ensino técnico oferecia e o que as empresas necessitavam em termos de formação. Daí a proposta de que tal ensino se "desescolarizasse", voltando-se mais diretamente para as necessidades do mercado.

5. Na discussão dos aspectos da vida institucional do IfsP que, de um lado, marcaram a implementação das reformas educacionais apoiadas nos decretos n. 2.208/97 e 5.154/04 e, de outro, foram por elas afetados, vali-me, para a produção deste artigo, além das pesquisas realizadas pelos próprios professores do IFSP, de outras realizadas em IF localizados em outros estados, de modo a verificar a existência de semelhanças e diferenças entre os resultados encontrados. Vale ressaltar que, à exceção da pesquisa de Oliveira (2002), as demais, produzidas sobre outros IF que não o de São Paulo, foram concluídas entre 2009 e 2010.

6. O termo retoma parece-me inadequado, pois dá margem a que se interprete o ensino médio integrado na mesma perspectiva assumida pelos professores do IFSP, ou seja, como o retorno ao ET/71, o que, pelo teor do texto, não parece ser a perspectiva da autora. 


\section{Referências}

BALL, S. La micropolítica de la escuela: hacia una teoría de la organización escolar. Madrid: Centro de Publicaciones del Ministerio de Educación y Ciencia; Barcelona: Paidós, 1989.

D’ANGELO, M. Escola Técnica Federal de São Paulo: a integração do saber e do fazer na formação do técnico de nível médio (1965-1986). 2007. Tese (Doutorado em História Social) - Departamento de História, Faculdade de Filosofia, Ciências e Letras, Universidade de São Paulo, São Paulo.

DUGUÉ, E. A gestão das competências: os saberes desvalorizados, o poder ocultado. In: Desaulniers, J. Trabalho E formação E competências. Porto Alegre: edipucrs, 1998. p. 101-132.

FERRETTI, C.J. Formação profissional e reforma do ensino técnico: anos 90. Educação $\mathcal{E}$ Sociedade, Campinas, v. 18, n. 59, p. 225-269, 1997.

FERNANDES, C.M. As políticas curriculares na cotidianidade da escola: a análise dos professores sobre o impacto da reforma na educação profissional do CEFET-SP. 2007. Dissertação (Mestrado em Educação) - Programa de Pós-Graduação em Educação, Centro Universitário Moura Lacerda, Ribeirão Preto.

FRIGOTTO, G.; CIAVATTA, M.; RAMOS, M. (Org.). Ensino Médio Integrado: concepções e contradições. São Paulo: Cortez, 2005.

GRISHKE, P.E.; HYPÓLITO, Á.M. Entre a gestão burocrática e o novo gerencialismo: a organização do trabalho docente na educação profissional. Trabalho $\mathcal{E}$ Educação, Belo Horizonte, v. 18, p. 1-11, 2009.

HADDAD, F. O Plano de Desenvolvimento da Educação: razões, princípios e programas. Brasília, DF: MEC/INEP, 2008

HIRATA, H. Da polarização das qualificações ao modelo das competências. In: FerRetTI, C. et al. (Org.). Tecnologias, trabalho e educação: um debate multidisciplinar. Petrópolis: Vozes, 1994. p. 124-134.

HYPÓLITO, A.M. Políticas curriculares, Estado e regulação. Educação E Sociedade, Campinas, v. 31, n. 113, p. 1337-1354, 2010.

KUENZER, A.Z. Ensino médio e profissional: as políticas do Estado neoliberal. São Paulo: Cortez, 1997.

KUENZER, A.Z. O ensino médio no Plano Nacional de Educação 2011-2020: superando a década perdida? Educação E Sociedade, Campinas, v. 31, n. 112, p. 851-874, 2010. 
LIMA FILHO, D.L. Impactos das recentes políticas de educação e formação dos trabalhadores: desescolarização e empresariamento da educação profissional. Perspectiva, Florianópolis, v. 20, n. 2, p. 269-301, 2002.

LUKÁCS, G. Per una ontologia dell'essere sociale. Roma: Riuniti, 1981.

MACHADO, L. Educação básica, empregabilidade e competência. Trabalho \& Educação, Belo Horizonte, n. 3, p. 15-34, 1998.

MATIAS, C.R. Reforma da Educação Profissional: implicações da unidade - Sertãozinho do CEFET-SP. 2004. Dissertação (Mestrado em Educação) - Programa de Pós-Graduação em Educação, Centro Universitário Moura Lacerda, Ribeirão Preto.

MERGULHÃO, V.L.M. O Centro Federal de Educação Tecnológica de São Paulo: ilha do saber ou mar de incertezas? 2003. Dissertação (Mestrado em Educação) - Programa de Pós-Graduação em Educação, Faculdade de Educação, Universidade de São Paulo, São Paulo.

NESSRALLA, M.R.D. Currículo integrado do ensino médio com a educação profissional tecnológica: da utopia à concretização do currículo possível. 2010. Dissertação (Mestrado em Educação Tecnológica) - Centro Federal de Educação Tecnológica de Minas Gerais, Belo Horizonte.

OLIVEIRA, M.A.M. A reforma do ensino profissional: desmantelamento da educação tecnológica ministrada pelo cefet-? Revista dos Reitores, Brasília, DF, v. 46, p. 23-42, 2002.

PEREIRA, U.Á. Política de educação profissional técnica e de ensino médio no Brasil: a implementação no CEFET-RN (1998-2008). 2010. Tese (Doutorado em Educação) - Programa de Pós-Graduação em Educação, Universidade Federal do Rio Grande do Norte, Natal.

RODRIGUES, D.D. A experiência de integração curricular no Instituto Federal de Educação, Ciência e Tecnologia do Mato Grosso campus/Cáceres. 2010. Dissertação (Mestrado em Educação) - Programa de Pós-Graduação em Educação Agrícola, Universidade Federal Rural do Rio de Janeiro, Rio de Janeiro.

ROPÉ, F.; TANGUY, L. (Org.). Saberes e competências: o uso de tais noções na escola e na empresa. Campinas: Papirus, 1997.

VILLELA, J.E.N. Oportunidades e desafios dos Centros Federais de Educação Tecnológica: estudo de caso do CEFEt/sp. 2007. Dissertação (Mestrado em Educação) - Programa de Pós-Graduação em Educação, Universidade de Santo Amaro, Santo Amaro.

VIROTE, S.M.P. A educação profissional técnica de nível médio integrada ao ensino médio: 
implicações das mudanças legais no governo Lula para o IFG. 2009. Dissertação (Mestrado em Educação) - Universidade Católica de Goiás, Goiânia.

\section{Documento}

BRASIL. Lei n. 11.892, de 29 de dezembro de 2008. Institui a Rede Federal de Educação Profissional, Científica e Tecnológica, cria os Institutos Federais de Educação, Ciência e Tecnologia, e dá outras providências. Brasília, DF, 2008.

Recebido em 30 de junho de 2011.

Aprovado em 3 de agosto de 2011. 